\title{
$X$. The Bakerian Lecture. On the relations of electrical and chemical changes
}

\section{Sir Humphry Davy Bart. Pres. R.S.}

To cite this article: Sir Humphry Davy Bart. Pres. R.S. (1827) X. The Bakerian Lecture. On the relations of electrical and chemical changes, Philosophical Magazine Series 2, 1:1, 31-38, DOI: 10.1080/14786442708674202

To link to this article: http://dx.doi.org/10.1080/14786442708674202

曲 Published online: 10 Jul 2009.

Submit your article to this journal $₫$

Џll Article views: 3

View related articles $\llbracket$ 
So far as the case of the present eclipse bears upon the question, I tried this with respect to the extreme red rays discovered by Mr. Herschel, to which the greatest heating power belongs; and looking at the sun during the eclipse through a good prism of flint glass, interposing before the eye three thicknesses of the purple glass, described by that gentleman, I saw the ray in question perfectly distinct, and unaltered as compared with its appearance when there was no eclipse.

The deep red image of the sun thus forming the end of the spectrum, of course exhibited the eclipse; and in a spectrum formed in a darkened room, if the superposition was but small, the same deficiency at the red end might be apparent; but this obviously would not explain a deficiency of heat as compared with that of the compound rays; nor would it account for the increased brilliancy which Mr. Wiseman observed in the yellow and blue.

I am not aware what was the cause reasoned upon by $\mathrm{Mr}$. $W$. as capable of producing any actual relative deficiency of red rays: if it were any such cause as inflexion of the sun's light in passing the body of the moon, which should affect the red rays most, and thus the light reaching the earth should be deprived of a portion of red, a less portion of green, blue, \&c. this would produce a diminution in intensity, though not a deficiency in space, in the red part of the spectrum. Hence, however, would result a greater relative brightness in the blue, \&c.; and such a difference in the heating effects as has been described. Such a cause would act more sensibly in porportion to the magnitude of the eclipse; and its effects might be quite insensible, except in a very considerable eclipse.

X. The Bakerian Lecture. On the Relations of Electrical and Chemical Changes. By Sir Humphry Davy, Bart. Pres. R.S.*

\section{Introduction.}

A LONG time has elapsed since I read before this Society A the Bakerian Lecture on the Chemical Agencies of Electricity. The general laws of decomposition developed in that paper were immediately illustrated by some practical results, which the Society did me the honour to receive in a very favourable manner; and which, by offering a class of new and powerful agents, led me away for many years into a field of

* From the Philosophical Transactions for 1826. Part III. 
pure chemical inquiry : and it is only lately, and on an occasion which is well known, that I have again taken up the subject of the general principles of electro-chemical action. After a number of new experiments, which I shall have the pleasure of laying before the Society, and notwithstanding the various novel views which have been brought forward in this and in other countries, and the great activity and extension of science, it is peculiarly satisfactory to me to find that I have nothing to alter in the fundamental theory laid down in my original communication; and which, after a lapse of twenty years, has continued, as it was in the beginning, the guide and foundation of all my researches.

I am the more inclined to bring forward these new labours at the present moment, though they are far from being in a finished state, because the discovery of Oersted and that of Morichini, illustrated by some late ingenious inquiries, connect the electro-chemical changes with entirely new classes of facts, and induce a hope that many of the complicated phænomena of corpuscular changes, now obscure, will ultimately be found to depend upon the same causes, and to be governed by the same laws; and that the simplicity of our scientific arrangements will increase with every advance in the true knowledge of nature.

\section{Some historical details.}

As I am not acquainted with any work in which full and accurate statements on the origin and progress of electrochemical science are to be found, and as some very erroneous statements have been published abroad, and repeated in this country, I shall take the liberty of laying before the Society a short historical sketch on this subject; which is the more wanted, as the journal in which the early discoveries were registered has long been discontinued, and is now little known or referred to.

As there are historians of chemistry and astronomy who date the origin of these sciences from antediluvian times, so there are not wanting persons who imagine the origin of electro-chemical science before the discovery of the pile of Volta; and Ritter and Winterl have been quoted * amongst other persons as having imagined, or anticipated the relation between electrical powers and chemical affinities, before the period of this great invention. But whoever will read with attention Ritter's " Evidence that the galvanic action exists in organized Naturet," and Winterl's "Protusiones ad Chemiam Saculi decimi noni," will find nothing to justify this

* Oersted, translated by Marcel, $1813 . \quad \quad+$ Jena, 1800.

opinion. 
opinion. Ritter's work contains some very ingenious and original experiments on the formation and powers of single galvanic circles; and Winterl's some bold, though loose speculative views* upon the primary causes of chemical phænomena: and in the obscurity of the language and metaphysics of both these gentlemen, it is difficult to say what may not be found. In the ingenious, though wild views, and often inexact experiments of Ritter, there are more hints which may be considered as applying to electro-magnetism than to electrochemistry; and Winterl's miraculous Andronia might, with as much propriety, be considered as a type of all the chemical substances that have been since discovered, as his view of the antagonist powers, the acid and basic, can be regarded as an anticipation of the electro-chemical theory. The queries of Newton at the end of his "Optics" contain more grand and speculative views that might be brought to bear upon this question than any found in the works of modern electricians $\nmid$; but it is very unjust to the experimentalists who, by the laborious application of new instruments, have discovered novel facts and analogies, to refer them to any such suppositions as, "that all attractions, chemical $\ddagger$, electrical, magnetic, and gravitative, may depend upon the same cause;" or to still looser

- As a specimen of the Prolusiones, 1 shall give a few articles from the index, which will show the character of the work. Prolusiones, pag. 256, et seq.

256. "Adamas est Andronia.

260. "Andronia cum Plumbo creat Barytam, cum Ferro Chalybem.

262. "Carbo est acidus cum Atmosphæra basica.

263. "Chromium non est nisi Calx Magnesii acida.

- "Cuprum cum Androniâ coalescit in Moybdænum.

268. "Scintilla electrica formatur à Principiis Conductorem primum et secundum animantibus, ac inter se concurrentibus; est gravis, habet effectum electricitati contrarium."

+ See the eloquent observations of $M$. Chenevix on the subject of Winterl's Theory, Annales de Chimie, vol. 50, 2 cap. 175.

$\ddagger$ In the Systême Universelle of M. Azais, not only are all the phænomena of nature referred to the same cause, but specific reasonings upon the mode of its operation given. In this work, published in 1810 , not only is the identity of magnetism and electricity insisted on, but an attempt is made to explain the manner in which the two electrical fluids produce the magnetic phænomena, pag. 239, vol. i. " Ainsi ces deux ordres de phénomènes sont tres resemblans. Repetons que toutes leurs différences résultent uniquement de ce que les deux fluides sont moins intenses lorsqu'ils produisent les phénomènes du Magnétisme que lorsqu'ils produisent les phénomènes du Galvanisme, \&c." It requires only the same principle as that censured in the text to refer to this author the discovery of Oersted and the speculations of Ampère. M. Azais, in his " fluides mineure et majeure," finds all the causes of the acid and alkaline properties of bodies:-slow combinations, the heat produced, and all the phænomena of chemical change; and his reasonings are often very ingenious.

New Series Vol. 1. No.1. Jan. 1827. F expres- 
expressions, in which different words are used and applied to the same ideas, and in which all the phænomena of nature are supposed to depend on the Dynamic system, or the equilibrium and opposition of antagonist powers.

The true origin of all that has been done in electro-chemical science was the accidental discovery of MM. Nicholson and Carlisle, of the decomposition of water by the pile of Volta, April 30, 1800*. These gentlemen immediately added to this capital fact, the knowledge of the decomposition of certain metallic solutions, and the circumstance of the separation of alkali on the negative plates of the apparatus. Mr. Cruickshank, in pursuing their experiments, added to them many important new results, such as the decompositions of muriates of magnesia, soda and ammonia, by the pile; and that alkaline matter always appeared at the negative, and acid at the positive pole $t$ : and Dr. Henry about the same time made some unsuccessful attempts to decompose potassa in soIntion by the pile, and confirmed the general conclusions of MM. Nicholson, Carlisle, and Cruickshank. In the month of September in this year, I published my first paper on the subject of Galvanic Electricity, in Nicholson's Journal, which was followed by six others $\neq$ : the last of which appeared in January 1801. In these papers I showed that oxygen and hydrogen were evolved from separate portions of water, though vegetable and even animal substances intervened; and conceiving that all decompositions might be polar $\oint$, I electrised different compounds at the different extremities, and found that sulphur and metallic substances appeared at the negative pole, and oxygen and azote at the positive pole, though the bodies furnishing them were separate from each other. In the same series of papers I established the intimate connexion between the electrical effects and the chemical changes going on in the pile, and drew the conclusion of the dependence of one upon the other. In 1802 I proved that galvanic combinations might be formed from single metals, or charcoal and different fluids chiefly acid and alkaline, and that the side or pole of the conducting substance in contact with the alkali was positive, and that in contact with the acid, negative; and in the same year I published, that when two separate portions of water, connected by moist bladder or muscular fibre, were electrised, nitro-muriatic acid appeared at the positive, and fixed alkali at the negative pole $\oint$. In the same year Dr. Wollaston placed the identity of the cause of

* Nicholson's Journal, vol, xlii. p. 183.

$\uparrow$ Ibid. vol. iv. p. 190.

+ Ibid. pp. 275, 326, 337, 394, 380 .

$\oint$ Journal of the Royal Institution, 1802. First Series. 
galvanism and electricity, which had been always maintained by Volta, out of all doubt, by some very decisive experiments.

In 1804, MM. Hisinger and Berzelius stated that neutrosaline solutions were decomposed by electricity, and the acid matter separated at the positive, and the alkaline matter at the negative poles; and they asserted that in this way muriate of lime might bedecomposed; and drew the conclusion that nascent hydrogen was not, as had been generally believed, the cause of the appearance of metals from metallic solutions. These valuable observations ought to have explained distinctly the source of the appearance of acid and alkaline substances at the two extremities of the pile; yet the paper was never translated into English, nor at all attended to; and one of their facts was contradicted by the assertion of, generally, a very accurate observer, Mr. Cruickshank, who in his early experiments mentioned that he had not been able to decompose muriate of lime in the circuit.

In 1805 various statements were made, both in Italy and England, respecting the generation of muriatic acid and fixed alkali from pure water. The fact was asserted by MM. Pacchioni and Peele, and denied by Dr. Wollaston, M. Biot, and the Galvanic Society at Paris*. Mr. Sylvester, who conducted his experiments with some care, stated, that if two separate portions of water were electrised out of the contact of substances containing alkaline or acid matter, acid and alkali were generated; so that up to this time the question, whether these substances were liberated from their combinations, or formed from their elements by electricity, could not be considered as decided : a circumstance not so much to be wondered at, when the novel and extraordinary nature of the whole class of galvanic phænomena is considered.

It was in the beginning of 1806 t that I attempted the solution of this question; and after some months' labour I presented to the Society the Dissertation, to which I have re-

- Some writers have very incorrectly referred the origin of these researches to the observations of Hisinger and Berzelius; Annales de Chim. vol. li. 1 cap. pag. 167 ; but these observations were never quoted by any writer of the day on the pretended production of muriatic acid and alkali; and I was not acquainted with them till after my fundamental experiments were finished; and, when in drawing up an account of them, I looked back through the whole series of periodical publications to find accounts of experiments bearing upon the same question, and I believe I first directed the public attention to the value of those researches. Whoever will take the tronble to read the Bakerian Lecture for 1806, will be convinced of the gradual development of the whole subject from the investiga. tion respecting the pretended formation of muriatic acid and fixed alkali.

+ Phil. Trans. 1807. 
ferred in the beginning of this Lecture. Finding that acid and alkaline substances, even when existing in the most solid combinations, or in the smallest proportion in the hardest bodies, were elicited by voltaic electricity, I established that they were the results of decomposition, and not of composition or generation; and referring to my experiments of 1800 and 1801 and 1802, and to a number of new facts, which showed that inflammable substances and oxygen, alkalies and acids, and oxidable and noble metals, were in electrical relations of positive and negative, I drew the conclusion, that the combinations and decompositions by electricity were referrible to the law of electrical attractions and repulsions, and advanced the hypothesis, "that chemical and electrical attraction were produced by the same cause, acting in one case on particles, in the other on masses," and that the same property, under different modifications, was the cause of all the phanomena exhibited by different voltaic combinations.

Believing that our philosophical systems are exceedingly imperfect, I never attached much importance to this hypothesis; but having formed it after a copious induction of facts, and having gained immediately by the application of it a number of practical results, and considering myself as much the author of it as I was of the decomposition of the alkalies, and having developed it in an elementary work, as far as the present state of chemistry seemed to allow, I have never criticized or examined the manner in which different authors have adopted or explained it,-contented, if in the hands of others it assisted the arrangements of chemistry or minera$\operatorname{logy}$, or became an instrument of discovery. And having now given what I believe to be a faithful sketch of its origin, I shall not enter into an examination of those works which have induced me to make this sketch, and which contain partial or loose statements on the subject, and which refer the origin of electro-chemistry to Germany, Sweden and France, rather than to Italy and England, and which attribute some of the views of the science, which I first developed, to philosophers who have never made any claim of the kind, and who never could have made any, as their works on the subject were published many years after 1806 .

\section{On the modes adopted for detecting the electrical states of bodies, and definitions of terms.}

That the statements made in the following sections may be more distinct, I shall say a few words of the mode in which the different conditions of electrical action were ascertained, 
and describe the manner in which $I$ have used the terms which have been adopted in electro-chemical science.

In determining the nature of the electrical action in what may be called the closed circle, or the combinations in which, according to the language used on the continent, electrical currents exist, I have employed instruments constructed upon the same principles as the galvanometer of Professor Cumming, or the multiplier of Professor Schweigger. Silver wire, covered with silk, about 1-70th of an inch in diameter, was folded round a small wooden frame, so as to fill a narrow deep groove: the two extreme wires were parallel, and the convolutions as nearly as possible in the same perpendicular: a small tube containing a filament of silk was passed through the centre of the convolutions of wires, to which a delicate magnetised needle was suspended ; which, when the apparatus was properly disposed, rested with its north pole between the two extremities of the wires. This instrument, which contained 60 circumvolutions of wire, was found sufficiently delicate for most purposes of experiment; but in a few instances, in which very weak electricities were to be determined, I used another apparatus, in which the same kind of wire was fastened, in concentric circles, round two portions of glass tube, in such a manner that radii from the inner circle would have passed through all the wires, and in which increased mobility was given to the system by two needles exterior to it and connected with it, placed one above, the other below the central needle, with their poles in the same directions, but opposite to those of the central needle, which was so magnetised that its directive power was neutralised by the power of the other two needles*.

To illustrate the operation of these apparatus, I shall state, that when the lower terminating wire, which was to the left, or east of the north pole, was connected with a piece of zinc, and the upper one with a piece of platinum, both being in common water, the deviation of the central needle was eight or ten degrees, the south pole turning to the east or left hand; which may be considered as indicating that the current of electricity was from the platinum to the zinc through the wire, and that the surface of the zinc in the fluid was positive with respect to the opposite surface of platinum; and in using the terms positive and negative, I beg to be understood as applying them to the metallic surfaces in contact with the fluid.

* This arrangement differs from that of M. Nobile only by a duplication of effect.

For 
For determining weak electricities of charge, or as it is sometimes called, of tension, I used Volta's condenser connected with Bennet's electrometer, and sometimes with one constructed on the principle of Behrens, consisting of an insulated gold leaf, or what I found better, a silk filament, made conducting by impalpable charcoal powder, to receive the charge, placed between the poles of a dry pile consisting of 400 circles of silver and gold foil, of the third of an inch in diameter, or 50 of zinc and silver of the same size, with paper intervening; the attraction of the gold leaf or the filament, either to the positive or negative pole, indicates the nature of the charge: and, as in cases of electro-chemical action there are always two corresponding opposite states, I considered the part of the system which touched the conductor as possessing the same electrical state with that exhibited by the leaf. I have never however put much dependence upon indications given by this instrument, unless they were confirmed by other results; having found them very uncertain, and influenced by the state of the condenser and the atmosphere.

[To be continued.]

XI. Observations on a Mineral from near Hay Tor, in Devonshire. By Cornelius Tripe, Esq.*

WHILE mineralogical science is so extensively cultivated, and rapidly increasing in interest and importance, the following brief description of a newly discovered mineral substance may not be unacceptable to the readers of the Philosophical Magazine.

The mineral alluded to was found in detached pieces, accompanied by small masses of chalcedony, garnet, actynolite, talc, and very splendent octohedral oxidulated iron. These substances, altogether, formed a single bunch of inconsiderable size enveloped by a ferruginous clay, in a large lode of very pure oxidulated iron, in an iron mine adjacent to the Hay Tor granite quarries, Devonshire.

Mr. Kennard, a respectable mineral dealer of Devonport, personally assisted in removing the mineral from its situation; and possesses the greater part which has been raised. I have myself examined the mine since; but with the most attentive observation could not detect any further trace of the substance, nor of the massive chalcedony, actynolite, or garnet, which, as already stated, was found associated with it.

The crystals, which are generally large and well defined,

* Communicated by the Author. 